\title{
Neuroplasticidade e a Recuperação da Função após Lesões Cerebrais
}

\author{
José Brenha Ribeiro Sobrinho*
}

As lesões cerebrais são talvez as que provoquem maiores e mais extensos déficits funcionais no ser humano.

As células nervosas perdidas não podem ser regeneradas por divisão celular e a possibilidade de neoformação de seus prolongamentos citoplasmáticos condutores de estímulos (dendritos e axônios) é limitada pela cicatrização do foco lesional, fenômeno este que começa alguns dias após a lesão, sendo o crescimento axonal suspenso 2 semanas após ${ }^{2}$ a lesão. Via de regra, as lesões cerebrais mesmo focais provocam disfunções, paralisias e déficits que acometem várias modalidades das inúmeras funções do cérebro, funções estas que garantem no ser humano a sua insuperável adaptabilidade aos mais diversos e inóspitos ambientes.

Entretanto, por graves que sejam as conseqüências destas lesões, observam-se que freqüentemente ocorrem melhoras nos déficits funcionais; em alguns casos, já nos primeiros meses de evolução do doente e em outros, após vários meses ou até mesmo anos.

Estas recuperações funcionais são via de regra parciais e funcionalmente pouco eficazes ${ }^{4}$, mas de qualquer maneira denotam uma capacidade do sistema nervoso e particularmente do cérebro de desenvolver mecanismos adaptativos para levar a cabo a sua função integradora entre o meio ambiente e o indivíduo.

Este complexo de mecanismos adaptativos que permitem a recuperação parcial das funções corticais é a manifestação de uma propriedade intrínseca do sistema nervoso que é o de modificar a sua organização estrutural e funcional em resposta a estimulações reiteradas.

Este mecanismo é denominado plasticidade. A plasticidade cerebral é o meio pelo qual o organismo cria modificações funcionais duradoras permitindo a acomodação entre os desafios do meio e as possibilidades do indivíduo.

A outra propriedade fundamental do sistema nervoso é a excitabilidade que está relacionada com mudanças adaptativas rápidas, que não deixam traços de memória no sistema nervoso.

\footnotetext{
* Médico Fisiatra da Divisão de Medicina de Reabilitação do Hospital das Clínicas da Faculdade de Medicina da Universidade de São Paulo.
} 
Nas páginas que seguirem, vamos abordar os possíveis mecanismos através dos quais o sistema nervoso manifesta a sua propriedade plástica. Faremos a distinção entre a recuperação funcional secundária, a neuroplasticidade e à devida a volta à atividade de circuitos cerebrais indenes, mas funcionalmente inibidos.

\section{Bases Estruturais e Funcionais da Plasticidade Cerebral}

O cérebro pode ser encarado como um sistema que analisa e sintetiza as informações do meio externo e interno, compara os dados obtidos com os traços de memória, criando representações complexas (multimodais) das diferentes situações com as quais o indivíduo se defronta e, a partir do complexo de informações integradas com o repertório mnéstico, cria e executa esquemas de ação, tendo como meta a satisfação das necessidades do indivíduo ${ }^{1}$.

A causa, o móbil, da ação integrada da atividade cerebral é a preservação do organismo, feita através dos diferentes instintos fundamentais e dos reflexos condicionados elaborados a partir destes instintos.

As diferentes manifestações da atividade cerebral, quer no campo perceptivo, quer no campo motor não podem ser localizadas em áreas discretas do cérebro, sendo sim resultado da atividade integrada de todo o cérebro.

Entretanto, isto não quer dizer que a estrutura cerebral seja uniforme. Muito pelo contrário, tanto o número de camadas do córtex como a proporção de cada um dos diversos tipos celulares e conseqüentemente os tipos de circuitos axo somáticos e axo dendríticos variam de uma região cerebral para a outra.

Podemos, por exemplo, de maneira simples, dividir as áreas corticais: arquicórtex, paleocórtex, córtex intermediário (meso córtex) e neocórtex.

$\mathrm{O}$ arqui e paleocórtex apresentam apenas três camadas ao invés das seis do neocórtex. O número de tipos celulares bem como a estrutura sináptica é também mais simples que a do neocórtex.

Já o neocórtex apresenta seis camadas estruturadas e cada uma das várias regiões apresentam proporções diferentes dos diversos tipos celulares.

Se formos rigorosos na análise da diversidade estrutural do cérebro, chegaremos aos mapas de Brodmam com suas 54 áreas ou ao esquema de VOGT, com mais de uma centena ${ }^{2}$.

Atendo-nos ao neocórtex apenas será mais prático, e provavelmente mais fiel ao real, utilizarmos a classificação que considera o córtex formado basicamente por três tipos de áreas de complexidades morfofuncionais diferentes ${ }^{1}$.

As áreas primárias ou áreas de projeção são as responsáveis pela recepção das aferências intero e exteroceptivas e pelas eferências motoras e vicerais. Nestas áreas, predominam células de projeção ou de recepção com distribuição somatotípica, ligadas por assim dizer em série com o sistema nervoso periférico e com o restante da estrutura cerebral. Já as áreas secundárias apresentam um predomínio maior de células de axônios curtos e grande rede dendrítica, fornecendo o substrato estrutural para inúmeras ligações em paralelo com outros circuitos celulares. Além disso, as áreas secundárias apresentam, também, uma porção considerável de células de projeção para núcleos subcorticais tanto motores como sensitivos, e estes por sua vez projetam-se tanto para a periferia como novamente para o córtex, formando múltiplas vias paralelas de condução dos estímulos.

As áreas terciárias são as que apresentam um sistema mais rico de conexões em paralelo. Estruturalmente predominam as células de axônios curtos, formando nas camadas $2^{\circ}$ e $3^{\circ}$ uma verdadeira infinidade de circuitos alternativos, sendo que as células de projeção destas áreas além de serem proporcionalmente em número menor projetam-se preferentemente para outras áreas corticais (ainda que não exclusivamente).

Quando o cérebro é acometido por uma lesão localizada com perda de uma função (perceptiva ou motora) a capacidade do sistema de se reorganizar dependerá basicamente da existência ou não de circuitos neuronais alternativos que possam transmitir e substituir as estruturas morfofuncionais lesadas. Do que foi dito anteriormente, podemos concluir que áreas corticais diferentes apresentam níveis de plasticidade diferentes e conseqüentemente pacientes com lesões cerebrais diferentes terão possibilidades diversas de recuperação.

\section{Hipóteses sobre os mecanismos hísticos da plasticidade e alguns dados experimentais de importância para o futuro ${ }^{5}$.}

Os mecanismos através dos quais o cérebro humano se reorganiza são muito pouco conhecidos. As alterações histológicas encontradas não puderam até hoje ser relacionadas de modo inequívoco com a recuperação parcial das funções, havendo autores que supõem que certos tipos de alterações histológicas como o brotamento colateral de axônios hígidos e a sua nidação sináptica em células com aferência desconectadas provoquem mais distúrbios funcionais que melhoria do quadro seqüelar. 
Os estudos com animais de laboratório (especialmente em ratos e gatos) permitiram aventar algumas hipóteses sobre os principais mecanismos da plasticidade cerebral, fazendo-se sempre a ressalva de que estes dados devem ser aplicados analogicamente ao homem, com reservas, uma vez que a complexidade das funções humanas e a corticalização das funções do sistema nervoso central humano não encontram paralelo nestes animais.

Os mecanismos são:

1. Brotamento colateral: Axônios centrais geram brotos colaterais e assim formarem novas conexões, quando sistemas neuronais, com os quais eles dividem um mesmo destino polissináptico, tenha sido destruído.
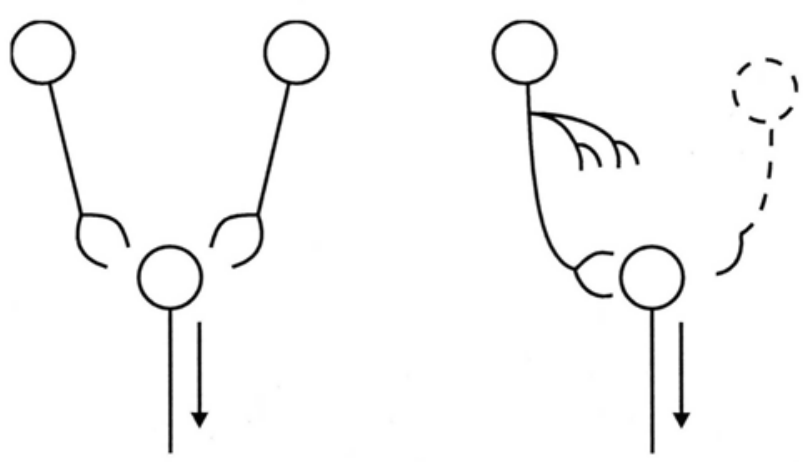

2. Supersensibilidade denervatória: Neurônios desnervados podem desenvolver supersensibilidade a mediadores químicos liberados sobre a fibra remanescente provocando muito mais efeito que o habitual. Assim, a função pode retornar pela reabertura do circuito parcialmente lesado.

3- Equipotencialidade ou ação de massa: Certas partes do SNC podem ter funções uniformes. Conseqüentemente, a quantidade de tecido lesado, mas não a sua localização será o determinante dos déficits após a lesão, sendo mediada pelo tecido remanescente.

4- Redundância ou vias alternativas: Certas funções podem ter múltiplos controles ou serem representadas em vários níveis no sistema nervoso central. A recuperação requer que um sistema intacto altere seu modo de operação para substituir as funções originalmente mediadas pelo tecido destruído.

A redundância subentende vias paralelas subordinadas à mesma função sendo que quando uma via é lesada a outra consegue suprir e "hipertrofiar-se".

Vias alternativas supõem que o sistema neural possua a capacidade latente de mediar certas funções não habitualmente dentro de sua esfera de competência. Apenas quando a via preferencial é perdida circuitos alternativos entram em ação.

Os dados anatomopatológicos e a observação clínica permitem imaginar como o meio preponderante através do qual se reorganizam as funções perdidas no ser humano, a redundância ou o mecanismo das vias alternativas. Este mecanismo explicaria em primeiro lugar a diferença de recuperação que ocorre em lesões cerebrais, envolvendo áreas distintas. Por exemplo, lesões localizadas em áreas primárias provocam perda definitiva da função, enquanto lesões em áreas secundárias e principalmente em áreas terciárias permitem recuperações por vezes impressionantes, desde que as lesões não acometam todo o tecido cortical da área correspondente. A hipótese da equipotencialidade ou da supersensibilidade não explicam esta diferença.

O mecanismo de brotamento colateral é admitido como um fenômeno presente na recuperação pós lesão cerebral. Entretanto, questionase se este mecanismo é um evento positivo ou não na recuperação, uma vez que só por acaso o motamento e as conseqüentes neossinapses no neurônio-alvo possibilitariam recuperar o sutil equilíbrio entre estímulos facilitatórios e inibitórios.

Por último, abordaremos a utilização de substâncias químicas na recuperação das lesões do SNC e o fenômeno da diasquisis.

\section{O Papel dos Mediadores Químicos na Recuperação dos Neurônios do S.N.C.}

$\mathrm{Um}$ dos fenômenos que intrigavam os pesquisadores da primeira metade do século $X X$, era o da diferença entre a capacidade de recuperação do sistema nervoso periférico (que freqüientemente consegue uma reparação parcial por crescimento axonal) e a capacidade extremamente limitada dos neurônios cerebrais e medulares de apresentarem crescimento axonal.

Uma tentativa para desvendar este mistério foi feito por Tello que trabalhando com Cajal em 1911, conseguiu um expressivo crescimento axonal de neurônios cerebrais em animais de laboratório. Para isso, Tello introduziu no cérebro dos animais segmentos de nervo ciático autólogo com células gliais viáveis. ${ }^{3}$

Ocorreu, como conseqüência desse enxerto, crescimento vigoroso e migrações dos axônios (utilizando o canal do nervo como ponte) através da cicatriz.

Como Cajal observou, na época, a importância deste fato residiu no fato de que ficou provado que o crescimento axonal de neurônios do S.N.C. não está irremediavelmente perdido, 
mas que estes poderiam ter suas funções tróficas influenciadas por alterações de seu microambiente.

Os fatores que influenciam o trofismo neuronal começaram a ser identificados há aproximadamente duas décadas, sendo o primeiro deste grupo de substâncias o fator de crescimento do nervo (N.G.F.). Esta substância é necessária para o crescimento e desenvolvimento de nervos do sistema simpático e nervos sensitivos e sua presença tem sido implicada na recuperação de alguns nervos. A origem do N.G.F é a glia do sistema nervoso periférico.

Outros fatores foram identificados nos últimos anos.

Estes novos elementos testemunham não só a potencialidade de recuperação através de substâncias químicas, como também são uma antevisão da complexidade do sistema modulador do trofismo e atividade neural que certamente estão por trás destas novas substâncias.

Assim, podemos classificar estes fatores em três grupos:

1) Fatores neurotróficos que mantêm e estimulam o crescimento geral de todo o neurônio.

2) Fatores estimuladores do axônio: que estimulam (provavelmente por ação local) o crescimento do axônio.

3) Fatores inibitórios que inibem o brotamento colateral.

Estes três grupos de fatores devem agir em conjunto, através de um sistema modulador ainda desconhecido, para garantir não só o crescimento mas também a orientação direcional do crescimento do neurônio.

$\mathrm{O}$ assunto fatores tróficos neurais é extenso e está ainda em sua fase inicial de pesquisa, escapando, portanto, ao propósito deste artigo.

\section{O Fenômeno da Diasquisis ${ }^{\top}$}

No início do século XX Van Monakow e Vedensky descreveram um fenômeno clínico intimamente relacionado com a reabilitação das lesões do sistema nervoso central.

Ambos trabalhando, independentemente, observaram que em pacientes com uma lesão cerebral aguda localizada ocorria perda da atividade de áreas corticais indenes. Estas áreas, embora histologica e estruturalmente preservadas, apresentavam-se funcionalmente comprometidas. Este estado de "assinapsia funcional" perdurava por períodos prolongados (06 meses), de acordo com o tipo de lesão. A este fenômeno Monakow denominou diasquisis e Vedensky de inibição parabiótica. Embora estruturalmente preservadas, a hipofunção ou ausência de função destas áreas em diasquisis comprometia a recuperação funcional, lentificando o processo de aprendizagem, impedindo a utilização de traços mnésticos e de áreas de projeção necessários ao processo pedagógico - reabilitador e, por isso, retardador dos fenômenos histológicos e neuroquímicos que são o substrato material da plasticidade cerebral.

Através da utilização de medicamentos como os anticolinesterásicos e as anfetaminas, bem como através da utilização de técnicas de facilitação neuromuscular pode-se diminuir o período de inibição funcional do tecido cerebral.

Em conclusão, podemos dizer que a plasticidade cerebral nos dias atuais tem como pilares a motivação e o exercício reabilitador, baseado em princípios neurofisiológicos e pedagógicos consagrados, e como principal fator limitante o acontecimento maciço das áreas de associação frontais.

No futuro, a ação criteriosa de psicoestimulantes associada aos neurohormônios ou fatores de crescimento neural poderá melhorar significativamente o processo de recuperação funcional dos pacientes com lesões cerebrais e medulares.

\section{Referências Bibliográficas}

1. LURIA, A.R. - Restoration of function after brain trauma macmillan. 1963

2. CAJAL, S.R. - Degeneration and Regeneraion of the Nervous Sistem. Oxford University Press, 1928.

3. ROBERTSON, MIRANDA. - The Unregenerate Nervous Sistem. Nature, Vol. 295 - 18 fevereiro 1982.

4. LASHLEY, K.S. - Factors Limiting Recovery After Central Nervous Lesions. The journal of nervous and mental disease. Dezembro 1938.

5. The central nervous sistem plasticity: WHO offset publication - n' 73,1983 - Genebra. 